\title{
Development of a Novel Functional Soup Rich in Bioactive Sulforaphane Using Broccoli (Brassica oleracea L. ssp. italica) Florets and Byproducts.
}

\author{
Laura Alvarez Jubete \\ Technological University Dublin, laura.alvarezjubete@tudublin.ie \\ Juan Valverde \\ Teagasc, juan.valverde@tudublin.ie \\ Kate Kehoe \\ Technological University Dublin
}

See next page for additional authors

Follow this and additional works at: https://arrow.tudublin.ie/schfsehart

Part of the Food Science Commons

\section{Recommended Citation}

Alvarez-Jubete, L., Valverde, J., Kehoe, K., Reilly, K., Rai, D. K. and Barry-Ryan, C. (2014), Development of a novel functional soup rich in bioactive sulforaphane using broccoli (Brassica oleracea L. ssp. italica) florets and byproducts. Food and bioprocess technology, May 2014, Volume 7, Issue 5, pp 1310-1321. doi:10.1007/s11947-013-1113-9

This Article is brought to you for free and open access by the School of Food Science and Environmental Health at ARROW@TU Dublin. It has been accepted for inclusion in Articles by an authorized administrator of ARROW@TU Dublin. For more information, please contact arrow.admin@tudublin.ie, aisling.coyne@tudublin.ie, gerard.connolly@tudublin.ie.

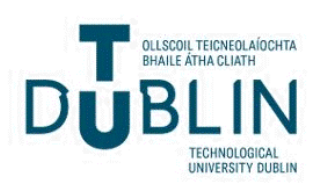




\section{Authors}

Laura Alvarez Jubete, Juan Valverde, Kate Kehoe, Kim Reilly, Dilip K. Rai, and Catherine Barry-Ryan

This article is available at ARROW@TU Dublin: https://arrow.tudublin.ie/schfsehart/205 


\title{
Development of a novel functional soup rich in bioactive sulforaphane using broccoli (Brassica oleracea L. ssp. italica) florets and byproducts
}

\author{
Alvarez-Jubete L ${ }^{\mathrm{a}}$, Valverde $\mathrm{J}^{\mathrm{b}}$, Kehoe $\mathrm{K}^{\mathrm{a}}$, Reilly $\mathrm{K}^{\mathrm{b}}$, Rai D. K. ${ }^{\mathrm{b}}$, Barry-Ryan $\mathrm{C}^{\mathrm{a} *}$ \\ ${ }^{\mathrm{a}}$ Department of Food Science, School of Food Science and Environmental Health, Dublin Institute of \\ Technology, Cathal Brugha St, Dublin 1, Ireland * corresponding author. \\ ${ }^{\mathrm{b}}$ Teagasc Food Research Centre, Ashtown, Dublin 15, Ireland
}

Abstract

Broccoli florets are rich in health-promoting compounds such as glucoraphanin, the precursor of the bioactive compound sulforaphane. In addition, broccoli byproducts such as broccoli stalk also contain health promoting compounds and represent attractive ingredients in the development of functional foods. The bioconversion of glucosinolates into bioactive isothiocyanates is affected by many factors including heat and therefore cooking of Brassicas such as broccoli may result in significant loss of sulforaphane production. The aim of this study was to develop a suitable food system as a vehicle for the delivery of sulforaphane in the human diet in adequate quantities. To this end, the feasibility of dry-mix ready soup as a food matrix for the delivery of broccoli floret and byproducts was evaluated. In particular, this study investigated the bioconversion of glucosinolates into bioactive isothiocyanates during the cooking process of this novel food product by microwave heating. In addition to total isothiocyanate and sulforaphane content, other key physical and biochemical quality attributes of the broccoli floret- and byproduct-enriched soups were investigated. These included colour, antioxidant capacity and sensory acceptability. Total isothiocyanate and sulforaphane content in floret- and stalk-enriched ready soups was high in both cases and increased in the order stalk $<$ floret which followed the trend observed in measured levels of glucoraphanin in stalk and floret respectively. The overall acceptability of stalk containing soups was not significantly different compared to the control soups, whereas floret containing soups received 
significantly lower acceptability scores. These results suggest that ready soups prepared by microwave heating represent a feasible food product for the delivery of broccoli florets and byproducts which is compatible with the bioconversion of glucosinolates into bioactive isothiocyanates.

Industrial relevance: Broccoli florets and broccoli byproducts have significant potential in the development of novel functional foods. Broccoli byproducts such as stalks offer significant advantages as they are currently considered rest-raw materials from agricultural and processing practices. Functional foods such as broccoli containing ready-soups represent adequate vehicle systems for the delivery and bioconversion of broccoli glucosinolates into isothiocyanates.

Keywords

Brassicas, broccoli, byproducts, glucosinolates, sulforaphane, total isothiocyanates, antioxidant capacity, and functional foods 


\section{Introduction}

Brassica vegetables have received significant attention in recent years due to their health promoting properties. Broccoli (Brassica oleracea L. ssp. italica) in particular contains a wide range of nutrients, micronutrients and phytochemicals (Jeffery \& Araya, 2009; Moreno, Carvajal, Lopez-Berenguer, \& Garcia-Viguera, 2006). The health properties of brassicas have been associated with isothiocyanates, a type of sulfur containing organic compounds formed in brassicas upon enzymatic hydrolysis. In particular, the isothiocyanate sulforaphane has been widely studied and has been demonstrated to have beneficial health effects. Sulforaphane (SFN) modes of action are well documented in the literature and have been reviewed elsewhere (Birgit Holst \& Williamson, 2004; Jeffery \& Araya, 2009; Verkerk et al., 2009; Y. Zhang \& Tang, 2007). In brief, SFN modulates many cancer-related events, including susceptibility to carcinogens, cell death, cell cycle, angiogenesis, invasion and metastasis (Y. Zhang \& Tang, 2007). Sulforaphane has also been shown to have anti-inflammatory effects inhibiting cytokine production (Jeffery \& Araya, 2009).

Isothiocyanates are not present as such in Brassicas. The precursors of isothiocyanates are a type of secondary metabolites named glucosinolate compounds ( $\beta$-D-thioglucose linked to a sulfonated oxime and a variable side chain). Brassica oleracea L. ssp. italica (broccoli) is particularly rich in glucoraphanin, the glucosinolate precursor of sulforaphane (Fahey, Zalcmann, \& Talalay, 2001; B. Holst, Fenwick, \& Benjamin, 2003). The enzyme responsible for the formation of isothiocyanates from glucosinolate precursors is an endogenous thioglucosidase enzyme named myrosinase (EC 3.2.3.1). Glucosinolates in plant tissues are physically separated from myrosinases (Verkerk, et al., 2009). However, upon tissue disruption, such as cutting, or mastication, glucosinolate compounds become in contact with the endogenous enzyme myrosinase (EC 3.2.3.1), which hydrolyses glucosinolates into isothiocyanates.

In addition to isothiocyanates, nitriles are also formed, as well as thiocyanates and epithionitriles to a smaller degree The type and ratio of the glucosinolate hydrolysis product depends on several factors such as the particular side chain of the glucosinolate and reaction conditions including temperature, $\mathrm{pH}$, ascorbic acid content and $\mathrm{Fe}^{2+}$ ions (Bones \& Rossiter, 2006). An important factor also known to affect the 
type and ratio of the glucosinolate hydrolysis products is a supplementary protein named epithiospecifier protein (ESP). ESP is a myrosinase co-factor that has been shown to affect the myrosinase-dependent glucoraphanin hydrolysis by directing the reaction towards the formation of sulforaphane nitrile in place of the isothiocyanate sulforaphane (N. V. Matusheski et al., 2006). Previous studies have shown that ESP activity varies depending on the type of Brassica plant and cultivar (Williams, Critchley, Pun, Chaliha, \& O'Hare, 2010). Also, the activity of ESP has been shown to be significantly affected by thermal treatment (N. V. Matusheski, Juvik, \& Jeffery, 2004). This is important from the food product development point of view as processing temperature can be therefore optimised to decrease ESP activity and direct the bioconversion towards the formation of bioactive sulforaphane over sulforaphane nitrile (N. V. Matusheski \& Jeffery, 2001). Also, heat processing stages should be adjusted to inactivate ESP while maintaining active myrosinase. Therefore, identifying compatible food preparation techniques that allow for the formation of sulforaphane in adequate quantities may be of great importance in the development of functional foods containing broccoli or broccoli byproducts.

A number of studies have evaluated the effect of domestic cooking practices such as steaming, boiling and microwave cooking on the glucosinolate content of broccoli (Jones, Frisina, Winkler, Imsic, \& Tomkins, 2010; Vallejo, Tomas-Barberan, \& Garcia-Viguera, 2002). These studies have reported significant losses of glucosinolates in floret tissue mainly due to leaching into the cooking water. Domestic cooking of broccoli such as steaming, boiling and microwave cooking has also been reported to significantly decrease sulforaphane production (Howard, Jeffery, Wallig, \& Klein, 1997; Jones, et al., 2010). In both studies, steaming was found to result in higher retention of sulforaphane production compared to the rest of the domestic cooking methods. Nonetheless, by 5 min steaming time sulforaphane levels were equivalent to those in unheated broccoli. Galgano, Favati, Caruso, Pietrafesa, \& Natella (2007) on the other hand showed how sulforaphane production was dramatically higher in broccoli tissue following microwave cooking compared to boiling and steaming. It is clear from these studies that sulforaphane production can be significantly reduced during domestic cooking and therefore special care must be taken to optimize cooking practices to ensure adequate levels of bioactive isothiocyanates are present in the final cooked product. 
Cooking is also known to induce changes in the antioxidant capacity of Brassicas such as broccoli. Microwave cooking in particular has been shown in a number of studies to negatively affect the levels of important antioxidant coumpounds such as vitamin C in broccoli (Vallejo, et al., 2002). Also, microwave cooking has been shown to reduce the antioxidant content of Brassica vegetables to a larger extent compared to steaming and boiling (Wachtel-Galor, Wong, \& Benzie, 2008). On the other hand, Zhang \& Hamauzu (2004) reported similar losses in antioxidant capacity during conventional (boiling) and microwave cooking: total antioxidant activity was retained at 34.7-35.0 \% in cooked florets and 34.6-34.7\% in cooked stalks. Similarly, Faller \& Fialho (2009) did not find significant differences in the antioxidant capacity of broccoli following boiling, steaming and microwaving. Moreover, a beneficial effect of cooking (boiling, steaming and frying) on the antioxidant capacity of broccoli has also been reported (Miglio, Chiavaro, Visconti, Fogliano, \& Pellegrini, 2008). This effect was attributed to an induced matrix softening effect caused by cooking, which results in increased extractability of compounds (Miglio, et al., 2008).

The aim of this study was to investigate the use of broccoli floret and byproducts in the preparation of novel convenience soups rich in phytochemical compounds. Broccoli byproducts include stalks and leaves and constitute approximately $50 \%$ of the broccoli crop (Rosa \& Rodrigues, 1999). The healthy and convenience food market is in expansion and the demand is increasing for functional food products that are healthy, convenient and of excellent quality in terms of flavour, texture and shelflife. A recent report by The Information Resources Inc. (IRI) states that "the heightened awareness and understanding of the important role food and beverages play in a healthy lifestyle by consumers will continue to drive the natural/organic, functional and better-for-you market for the foreseeable future” (Yuesheng Zhang, Wade, Prestera, \& Talalay, 1996). Also, as stated in a recent report by Leatherhead Food Research (1992) "Health has been a dominant trend in the UK over recent years, affecting the food and beverage industry through the re-formulation and introduction of new 'healthy(ier) style". The report also states "this trend shows no signs of abating with an increasing number of consumers indicating a greater awareness of health and well-being”. Convenience foods such as instant soups may provide an adequate vehicle for the inclusion of broccoli floret or broccoli byproducts to obtain a 
functional food enriched with phytochemical compounds for a number of reasons. The dried and stabilized freeze-dried broccoli powders can be directly incorporated into a dry-mix ready soup. Moreover, the preparation of the food product by adding cooking water and microwave heating may enable the conversion of glucosinolates into bioactive isothiocyanates thus resulting in the "in-situ" activation of the product by the consumer just before consuming, avoiding losses during storage. Commercial instant soups were enriched with broccoli floret or broccoli stalk and they were prepared using microwave cooking at several power levels and cooking times to render a final product with standard temperature. The resultant products were evaluated for key physical, sensorial and biochemical attributes including colour, sensory acceptability, antioxidant capacity as determined by the ORAC assay, total isothiocyanate content, and sulforaphane contents.

\section{Materials and methods}

\subsection{Chemicals}

2,2'-Azobis(2-methylpropionamidine) dihydrochloride (AAPH), mass spectrometry grade ammonium acetate, 1,2-benzenedithiol (BDT), fluorescein sodium salt, mass spectrometry grade formic acid, magnesium sulphate, potassium phosphate dibasic $\left(\mathrm{K}_{2} \mathrm{HPO}_{4}\right)$, potassium phosphate monobasic $\left(\mathrm{KH}_{2} \mathrm{PO}_{4}\right)$, silica gel, sodium chloride, sodium phosphate dibasic $\left(\mathrm{Na}_{2} \mathrm{HPO}_{4}\right)$, sodium phosphate monobasic $\left(\mathrm{NaH}_{2} \mathrm{PO}_{4}\right)$, DLsulforaphane (90\% purity), Trolox (6-hydroxy-2,5,7,8-tetramethylchroman-2carboxylic acid) were obtained from Sigma-Aldrich (Arklow, Ireland). Diatomaceous earth was purchased from Dionex (Idstein, Germany). Acetic acid and HPLC-grade solvents: acetonitrile, ethyl acetate, methanol, and water were purchased from BDH Ltd. (Poole, UK).

\subsection{Plant material}

Broccoli (Brassica oleracea L. ssp. italica cultivar Parthenon) was grown at Teagasc Horticultural Research Centre Kinsealy (Dublin, Ireland). Broccoli seeds were planted in late May 2011 and both broccoli florets, and stalks, were harvested in late July 2011. Samples were transported to Teagasc Food Research Centre Ashtown (Dublin, Ireland) were they were frozen and freeze-dried at $-50{ }^{\circ} \mathrm{C}$ and 0.03 mbar (Frozen in Time Ltd., York, UK). Lyophilised samples were milled, vacuum-packed and stored at $-20^{\circ} \mathrm{C}$ until analysis. 


\subsection{Preparation of the convenience soups}

Three different types of soups were prepared: control, broccoli floret-enriched and broccoli stalk-enriched soups. The control convenience soup was prepared using a cauliflower and broccoli commercial dry soup mix (Knorr QuickSoup Cauliflower and Broccoli, with a cauliflower and broccoli content of 4.6 and 1.5\% respectively according to the manufacturer). Broccoli floret-enriched and broccoli stalk-enriched soups were prepared by replacing $40 \%$ of the commercial dry soup mix with broccoli floret and stalk freeze-dried powders respectively. The inclusion level was estimated from preliminary trials that focused on establishing maximum inclusion level while preserving sensory aspects such as colour and overall appearance. The soups were prepared by adding $190 \mathrm{~mL}$ of cold ultrapure water to $20 \mathrm{~g}$ of dry soup mix (control, broccoli floret-enriched or broccoli-stalk enriched) and they were heated using a domestic microwave oven (Sharp E 800 W, Sharp Electronics Ltd, Uxbridge, UK). Different power and time combinations providing a total energy input of 50-56 KJ were tested. Verkerk \& Dekker (2004) have previously shown that the conversion of glucosinolates into isothiocyanates is not solely dependent on the energy applied and that different power - time combinations at the same energy input may yield different conversion rates. Thus, three cooking treatments were studied: $800 \mathrm{~W}$ for 70 seconds, 400W for 140 seconds and 240W for 210 seconds. For all microwave cooking treatments, the temperature reached in the final product was in the range of $63-65^{\circ} \mathrm{C}$. This temperature is adequate for consumption and at the same time is within the optimal conditions of enzymatic hydrolysis of glucosinolates by myrosinase (Song, Morrison, Botting, \& Thornalley, 2005) .

\subsection{Colour determination}

Colour was measured with a HunterLab spectrophotometer (ColourQuest XE, Hunter Associates Laboratory, Inc., Reston, VA) with a D65 illuminant and $10^{\circ}$ standard observer angle. The solutions were measured in reflectance mode using glass cells of $10 \mathrm{~mm}$ path length. The sample cells were appropriately covered to minimize the possibility of ambient light reaching the detector through the liquid sample during measurement. Colour coordinates were determined using the 1976 CIELAB system and the results were expressed as $\mathrm{L}^{*}$ (lightness), a* (redness) and $\mathrm{b}^{*}$ (yellowness). The instrument was calibrated before each series of measurements using white $\left(\mathrm{L}^{*}=\right.$ 
$\left.100, a^{*}=0, b^{*}=0\right)$ and black $\left(L^{*}=0, a^{*}=0, b^{*}=0\right)$ standard tiles. A numerical total colour difference $(\Delta \mathrm{E})$ was calculated as suggested by Jung, Ghoul \& De Lamballerie-Anton (2003):

$\Delta \mathrm{E}=\left[\left(\mathrm{L}^{*}-\mathrm{L}_{0} *\right)^{2}+\left(\mathrm{a}^{*}-\mathrm{a}_{0} *\right)^{2}+\left(\mathrm{b}^{*}-\mathrm{b}_{0} *\right)^{2}\right]^{1 / 2}=\left[(\Delta \mathrm{L} *)^{2}+\left(\Delta \mathrm{a}^{*}\right)^{2}+\left(\Delta \mathrm{b}^{*}\right)^{2}\right]^{1 / 2}$

The colour values of control samples $\left(\mathrm{L}_{0} *, \mathrm{a}_{0} *, \mathrm{~b}_{0}{ }^{*}\right)$ were used as reference values for $\Delta \mathrm{E}$ calculation. In addition, the Hue angle $\left(\mathrm{H}^{*}\right)$ was used as a parameter to describe colour and was calculated using the formula: $\mathrm{H}^{*}=\tan ^{-1}\left(\mathrm{~b}^{*} / \mathrm{a}^{*}\right)$. Hue angle is represented as a circumference where each angle corresponds to a different tint or colour tone, with red-purple at an angle of $0^{\circ}$, yellow at $90^{\circ}$, bluish-green at $180^{\circ}$, and blue at $270^{\circ}$ (McGuire, 1992). Chroma (C*, 0 at the centre of the colour sphere) is defined as the hypotenuse of the right-angle triangle created by $\mathrm{a}^{*}$ and $\mathrm{b}^{*}$ $\left(\left(\mathrm{a}^{2} / \mathrm{b}^{*^{2}}\right)^{1 / 2}\right)$. $\mathrm{C}^{*}$ is used to measure the intensity of a given $\mathrm{H}^{*}$ value. The higher the $\mathrm{C}^{*}$ the more intense the colour is. Three colour measurements were taken per sample.

2.5 Extraction and determination of in vitro antioxidant capacity by the ORAC method

Soup sample extracts for antioxidant capacity measurement were prepared by weighing $5 \mathrm{~g}$ of cooked soup sample into a centrifuge tube. Next, $4.5 \mathrm{ml}$ of $\mathrm{MeOH}$ were added to each tube. The centrifuge tubes were then vortexed for $20 \mathrm{~min}$, and centrifuged for $10 \mathrm{~min}$. Supernatants were filtered using $0.45 \mu \mathrm{m}$ PTFE filters and stored at $-40{ }^{\circ} \mathrm{C}$ until analysis. Three extracts were prepared per sample. The antioxidant capacity of the soup samples was determined using the ORAC assay as previously described by Huang, Ou, Hampsch-Woodill, Flanagan, \& Prior (2002). The principle of this ORAC assay is based on the free radical damage to a fluorescent probe, such as fluorescein, which results in a decrease in fluorescent intensity (Ou, Hampsch-Woodill, \& Prior, 2001). The presence of antioxidants inhibits free radical damage to the fluorescent compound therefore resulting in a preservation of the fluorescence intensity. The assay is driven to completion (total decay of fluorescence signal) and the antioxidant capacity is calculated by comparing the area under the curve (AUC) from the experimental sample to that of a calibration standard such as Trolox. The results are then expressed as Trolox equivalents (TE). By measuring the AUC, the antioxidant capacity as measured by the ORAC assay is an estimation of both inhibition time and inhibition percentage of the free radical damage by the antioxidant/s present (Huang, et al., 2002). 
Soup extracts (control, broccoli floret-enriched and broccoli stalk-enriched) were diluted 100 times in $75 \mathrm{mM}$ phosphate buffer ( $\mathrm{pH} 7.2$ ), and added in triplicate to a microtiter plate $(25 \mu \mathrm{L})$. Also, $25 \mu \mathrm{l}$ of Trolox standard solutions (6.25, 12.5, 25, 50 and $80 \mu \mathrm{M}$ ) were transferred in triplicate to the microtiter plate to build a Trolox calibration curve. The microtiter plate also contained a blank consisting of $25 \mu \mathrm{L}$ of $75 \mathrm{mM}$ phosphate buffer (pH 7.2). $150 \mu \mathrm{L}$ aliquots of Fluorescein solution (20 nM) prepared in $75 \mathrm{mM}$ phosphate buffer ( $\mathrm{pH}$ 7.2) were then added to all experimental wells. The outer wells were filled with $200 \mu \mathrm{L}$ of water to act as a heat mass and eliminate temperature fluctuations as recommended by the instrument's manufacturer (Biotek Application Note, Biotek Instruments, Vermont, USA). The ORAC assay was conducted in a Biotek Multi-Detection microplate reader (Biotek Instruments, Vermont, USA). The microtiter plate was introduced into the microplate reader and incubated at $37{ }^{\circ} \mathrm{C}$ for 30 min before the automated addition of $25 \mu \mathrm{L}$ of the radical generator AAPH (153 mM in $75 \mathrm{mM}$ phosphate buffer, $\mathrm{pH}$ 7.2) to all experimental wells with the exception of the blank wells. The plate was shaken for $10 \mathrm{~s}$ at maximum intensity and florescence was recorded every min for 90 min. Gen5 software (Biotek Instruments, Vermont, USA) was employed to integrate the area under the curve of the fluorescence decay and to calculate net AUC, Trolox calibration curve and antioxidant capacity of the samples under study (expressed as Trolox equivalents).

\subsection{Extraction and glucosinolate determination by Micellar Electrokinetic Capillary Chromatography (MECC) of freeze-dried broccoli floret and stalk powders}

Freeze-dried broccoli powders were extracted using pressurised liquid extraction with an ASE 200 instrument (Dionex, Sunnyvale, CA, USA) equipped with attached solvent controller. Extraction of $1.00 \mathrm{~g}$ freeze-dried broccoli was carried out in $22 \mathrm{~mL}$ steel cartridges. Extraction conditions were slightly modified from Mohn, Cutting, Ernst, \& Hamburger (2007). In brief, preheat time: 1 min; static extraction per cycle: 5 min; flush: $60 \%$ of cell volume; purge: 60 s with nitrogen; pressure: 120 bar. Glucotropaeolin (Phytolab GmbH,Vestenbergsgreuth, Germany) was used as an internal standard - $100 \mu \mathrm{L}$ of a solution of $0.5 \mu \mathrm{mol}$ of potassium salt of glucotropaeolin in Milli-Q water was spiked onto the sample packed in the ASE cell. 
The collected extract (ca $30 \mathrm{~mL}$ ) was dried under a constant $\mathrm{N}_{2}$ flow and re-dissolved in deionised water $(7 \mathrm{~mL})$.

For the determination of glucosinolates an aliquot of $1 \mathrm{~mL}$ of this crude extract was applied to a DEAE Sephadex A-25 column $(0.5 \mathrm{~mL})$ and the unbound material was removed by washing with deionised water $(2 \mathrm{x} 1 \mathrm{~mL})$ and sodium acetate buffer $(2 \mathrm{x}$ $0.5 \mathrm{~mL} ; 20 \mathrm{mM}, \mathrm{pH}$ 5.0). After washing, the purified sulphatase $(75 \mu \mathrm{L})$ was added and the columns were incubated overnight at room temperature. After overnight incubation, the desulphoglucosinolates (dGLS) were eluted from the columns with deionised water ( 3 x $1 \mathrm{~mL}$ ). The collected eluate was dried under constant $\mathrm{N}_{2}$ flow, redissolved in deionised water $(200 \mu \mathrm{L})$ and centrifuged prior to analysis. An aliquot of $50 \mu \mathrm{L}$ was used for micellar electrokinetic capillary chromatographic analysis.

MECC Analyses were performed using a CE capillary electrophoresis system (Agilent, Waldbronn, Germany) equipped with diode array detector. All separations were performed on a fused silica capillary (Agilent, Stevens Creek, CA; $75 \mathrm{~lm}$ ID, $64.5 \mathrm{~cm}$ total length, $56 \mathrm{~cm}$ effective length). Samples were injected from the anodic end of the capillary (vacuum injection, 50 mbar, $1 \mathrm{~s}$ ). The separation buffer consisted of sodium chlorate (250 mM) and boric acid (200 mM) at pH 8.5; the separation was carried out at $12 \mathrm{kV}$ and $60{ }^{\circ} \mathrm{C}$. The capillary was conditioned between each run sequentially with $1.0 \mathrm{M} \mathrm{NaOH}(3 \mathrm{~min}), 0.1 \mathrm{M} \mathrm{NaOH}(1 \mathrm{~min})$, water $(1 \mathrm{~min})$ and separation buffer (5 min). Detection was performed on column at 230 and $280 \mathrm{~nm}$. Data processing was carried out with 3D-CE Chemstation software (Agilent Waldbronn, Germany). The quantity of the dGLS was estimated as the average of quantities calculated from the internal standards, taking into account the relative response factors revised by Clarke (2009).

\subsection{Extraction for total isothiocyanate content and sulforaphane determination}

Soup sample extracts were prepared by liquid-liquid partitioning using ethyl acetate (2.5 g soup, $3 \mathrm{~mL}$ ethyl acetate). Magnesium sulphate was also added to obtain a saturated solution and therefore to facilitate the extraction of sulforaphane and sulforaphane nitrile into the ethyl acetate phase. Samples were then vortex for $20 \mathrm{~min}$ at $2000 \mathrm{rpm}$ and centrifuged for 5 minutes at 8,900 g and $4{ }^{\circ} \mathrm{C}$ (Sigma 2K15, Sigma, Ostrode, Germany). The ethyl acetate layer was then transferred to a clean test tube and the remaining aqueous phase was re-extracted with ethyl acetate as described 
above. This process was repeated one more time. The ethyl acetate layers were combined and dried using an EZ-2 Genevac centrifugal evaporator (Genevac SP Scientific, Ipswich, UK). The resultant residue was then re-suspended in $6 \mathrm{~mL} 70 \%$ methanol: $30 \%$ water, filtered through $0.22 \mu \mathrm{m}$ pore size PVDF membrane filters (Sigma Aldrich, St. Louis, USA) and stored at $-40{ }^{\circ} \mathrm{C}$ until analysis.

\subsection{Total isothiocyanate content}

Total isothiocyanate content was determined by UV-Vis spectrophotometry according with the method developed by Zhang, Cho, Posner, \& Talalay (1992). $900 \mu \mathrm{L}$ of 100 $\mathrm{mM}$ potassium phosphate buffer $(\mathrm{pH} 8.5), 100 \mu \mathrm{L}$ of sample or ITC standard (sulforaphane, Sigma Aldrich Chemical Co., St Luis, USA ) and $1 \mathrm{~mL}$ of $\mathrm{MeOH}$ containing 80 mM benzene-1,2-dithiol (BDT, Sigma Aldrich Chemical Co., St Luis, USA) were added to a $2.0 \mathrm{~mL}$ centrifuge tube. The mixture was then incubated for 90 min at $60{ }^{\circ} \mathrm{C}$. Samples were then cooled at room temperature and their absorbance was measured spectrophotometrically at $365 \mathrm{~nm}$. Quantification was achieved by means of a calibration curve prepared using sulforaphane standard (2.8-280 $\mu \mathrm{M})$. Total isothiocyanate content (TICN) was expressed as $\mu$ mol sulforaphane equivalents per gram of broccoli soup.

\subsection{UPLC-MS/MS determination of sulforaphane}

Chromatographic experiments were carried out on a Waters Acquity UPLC system managed by Acquity console software (Waters Corp., Milford, USA). Separation was achieved on a Waters Acquity BEH C8 column $(1.7 \mu \mathrm{M}, 2.1$ x $50 \mathrm{~mm})$ equipped with a Waters C8 VanGuard column (5mm x $2.1 \mathrm{~mm}$; $1.8 \mu \mathrm{m}$ particle size). The column temperature was maintained at $40{ }^{\circ} \mathrm{C}$ and the autosampler at $4{ }^{\circ} \mathrm{C}$. The mobile phase consisted of ammonium acetate buffer ( $10 \mathrm{mM}, \mathrm{pH}=4.5)$ (Mobile phase $\mathrm{A}$ ) and $0.1 \%$ formic acid in acetonitrile (Mobile phase B) at a flow rate of $0.5 \mathrm{~mL} / \mathrm{min}$ with an injection volume of $5 \mu \mathrm{L}$. The gradient conditions initially started at $30 \%$ (Mobile phase B) increasing over 1.5 min to $90 \% \mathrm{~B}$, held for $1 \mathrm{~min}$ at $90 \% \mathrm{~B}$ and finally reequilibrated to $30 \% \mathrm{~B}$ over $0.5 \mathrm{~min}$.

The UPLC system was attached to a tandem quadrupole mass spectrometer (Waters Acquity TQD, Waters Corp., Milford, USA). The instrument was operated in the ESI positive mode. The source temperature was set at $120^{\circ} \mathrm{C}$ and desolvation temperature was fixed at $350{ }^{\circ} \mathrm{C}$. Capillary voltage was set at $3 \mathrm{kV}$ and cone voltage was 
optimised for each of the compounds by using IntelliStart ${ }^{\mathrm{TM}}$ software (Waters Corp., Milford, USA). Nitrogen gas was used as both desolvation gas and declustering gas (800 L/hr and $50 \mathrm{~L} / \mathrm{hr}$ respectively). Detection of the analytes was conducted in the multiple reaction monitoring (MRM) mode by analysing two transition ions per compound. The MRM conditions were determined and optimised by tuning both sulforaphane and sulforaphane nitrile using Waters integrated IntelliStart ${ }^{\mathrm{TM}}$ software (Waters Corp., Milford, USA).

\subsection{Statistical analysis}

Statistical analysis was conducted using the SPSS software package (IBM SPSS Statistics v19, IBM Corporation, New York US). One way analysis of variance (ANOVA) was conducted to assess any differences between group means. In addition, data was analyzed by two-way ANOVA to study sample type, treatment and the sample type $\times$ treatment interaction as fixed effects. Differences were assessed using the Tukey test. Differences of $\mathrm{p}<0.05$ were considered significant.

\section{Results and discussion}

\subsection{Glucosinolate composition of broccoli floret and broccoli stalk}

The glucosinolate profiles of broccoli floret and byproducts (Parthenon cultivar) as determined in the present study are displayed in Table 1 . From these results, it can be observed that glucoraphanin content was highest $(\mathrm{p}<0.05)$ in broccoli floret followed by broccoli stalk and leaves. However, it is also important to note that when expressed as percentage of total glucosinolates, glucoraphanin content was significantly higher in stalks followed by floret and leaves. Thus, stalk and floret were selected for further investigation as ingredients in the development of functional soups in terms of bioactive content and sensory properties.

It can also be observed that glucoraphanin is the major glucosinolate in all floret, stalk and leaf tissue, followed by glucobrassicin, neoglucobrassicin and 4methoxyglucobrassicin. These results are in agreement with previously published data by Kushad, Brown et al. (1999). Kushad, Brown et al. (1999) studied the glucosinolate composition of 50 varieties of broccoli and reported that the predominant glucosinolates in broccoli were 4-methylsulfinylbutyl glucosinolate (glucoraphanin), 3-butenyl glucosinolate (gluconapin), and 3-indolylmethyl 
glucosinolate (glucobrassicin). According to the authors, glucoraphanin concentration in broccoli ranged from $0.8 \mu \mathrm{mol} / \mathrm{g}$ DW to $21.7 \mu \mathrm{mol} / \mathrm{g}$ DW and concentrations of the other glucosinolates in broccoli varied similarly over a wide range (Kushad, et al., 1999).

For broccoli floret tissue, similar glucoraphanin content to that found in the present study has been previously reported by Matusheski, Wallig et al. (2001) in a set of four broccoli commercial varieties, with values ranging between 5.0 and $7.1 \mu \mathrm{mol} / \mathrm{g} \mathrm{DW}$. Jones, Frisina et al. (2010) also reported glucoraphanin, glucobrassicin and neoglucobrassicin as the three most abundant glucosinolates found in the broccoli cultivars 'BoosterTM' and 'Marathon'. Content varied significantly between cultivars, with 'Booster ${ }^{\mathrm{TM}}$ ' having higher levels of glucoraphanin than 'Marathon' (28.6 and $13.1 \mu \mathrm{mol} / \mathrm{g}$ respectively). Glucobrassicin content was also higher in 'Booster ${ }^{\mathrm{TM}}$ ' compared to 'Marathon' (4.07 and $3.63 \mu \mathrm{mol} / \mathrm{g}$ respectively). The variation in glucosinolate profiles in broccoli varieties might be related to genetic, environmental and agricultural factors. Brown, Yousef et al. (2002) evaluated 10 broccoli accessions grown in several environments to estimate glucosinolate variability as affected by genotype, environment, and genotype $\times$ environment interaction. They identified significant differences in genetic variability for aliphatic but not for indolyl glucosinolates, which were found to be primarily regulated by environmental factors (Brown, et al., 2002).

\subsection{Soup colour}

The instrumental colour of the control, broccoli floret-enriched and broccoli stalkenriched soups is summarized in Table 2. It can be observed in Table 2 that differences exist in the colour parameters with regards to sample type. Results of the two-way ANOVA on the colour data revealed no interaction between sample type and treatment for $\mathrm{a}^{*}, \mathrm{~b}^{*}, \mathrm{H}^{*}, \Delta \mathrm{E}$ and $\mathrm{C}^{*}$ values. Cooking treatment as a fixed effect did not result significant for these colour parameters however a significant effect of sample type was observed (Table 4). The difference in colour between the broccoli enriched soups and the control soup, expressed as $\Delta \mathrm{E}$ values, was significantly higher for floret-enriched soups compared to stalk-enriched soups. Also, broccoli enriched soups had a significant increase in greenness $\left(-\mathrm{a}^{*}, \mathrm{H}^{*}\right)$ compared to the control soups. Greenness was highest $(\mathrm{p}<0.05)$ in broccoli floret-enriched soups followed by stalk- 
enriched soups. In addition, b* values were significantly lower for control soups, followed by stalk-enriched and floret-enriched soups, values which also contributed towards the observed significant change in $\mathrm{H}^{*}$ values towards green. Similarly, colour intensity or colour saturation (C*) also increased in the same manner control < stalkenriched < floret-enriched soups. A greener colour may represent an advantage from the visual quality point of view as consumers may regard a greener colour as an indicator of a higher quality product (higher vegetable content and more natural product). On the other hand, the milder green colour obtained in the case of stalkenriched soups may be preferred by a number of consumers whom may associate a milder green colour with a less intense green vegetable taste.

\subsection{Antioxidant capacity by ORAC assay}

Broccoli floret and byproducts may be used in the development of functional foods as a source of antioxidant compounds (Dominguez-Perles, Martinez-Ballesta, Carvajal, Garcia-Viguera, \& Moreno, 2010). The antioxidant capacity of broccoli floret and byproducts (stalk and leaves) was measured in this study by the ORAC assay. The highest antioxidant capacity was found for broccoli leaves extract (197.9 $\mu \mathrm{mol} \mathrm{TE} / \mathrm{g}$ DW), followed by broccoli floret (97.5 $\mu \mathrm{mol}$ TE/g DW) and broccoli stalk extracts (39.67 $\mu \mathrm{mol}$ TE/g DW). In a previous study by Dominguez-Perles, et al. (2010) broccoli also exhibited higher radical-scavenging activity in leaves compared to the stalks. Also, in the same study, the antioxidant capacity of the broccoli byproducts extracts measured by the DPPH· assay was found to be inversely correlated to vitamin C content. Broccoli phenolics on the other hand (determined by HPLC-DAD) were strongly correlated to the antioxidant capacity of the broccoli byproduct extracts and may thus possibly contribute to the observed radical-scavenging capacity in stalks and leaves (Dominguez-Perles et al, 2010).

The ORAC values for antioxidant capacity obtained in the present study for broccoli floret extracts are within the range of values reported in the literature. For instance, Kurilich, Jeffery, Juvik, Wallig, \& Klein (2002) evaluated the antioxidant capacity of hydrophilic extracts from eight broccoli genotypes using the ORAC assay and reported that the antioxidant capacity of hydrophilic extracts ranged from 65.8 to $121.6 \mu \mathrm{mol}$ trolox equivalents (TE)/g of broccoli DW. The antioxidant capacity measured was not fully explained by contributions from ascorbic acid and flavonoids 
thus other unidentified compounds present in the sample may therefore also contribute to the antioxidant capacity of the broccoli hydrophilic extracts. The authors also suggested the possibility of synergistic effects from the antioxidants identified such as vitamin C and flavonoids (Kurilich, et al., 2002).

The antioxidant capacities as measured by the ORAC assays of the control, broccoli floret-enriched and broccoli stalk-enriched soups are presented in Table 3. Antioxidant capacity of broccoli floret-enriched soups was slightly higher than the control soups, whereas in the case of broccoli stalk-enriched soups, the values were lower compared with the control soups. However, these differences were not statistically different.

The results of the two-way ANOVA on the ORAC data showed that there was no interaction between sample type and cooking treatment. Statistical analysis also revealed a non- significant effect for cooking treatment but a significant effect of the sample type with ORAC values in the order floret-enriched $>$ control $>$ stalk-enriched soups (Table 4). These results follow the trend observed for the ORAC values of broccoli floret and stalk extracts, where floret extracts were notably higher compared with those of stalk.

Dominguez-Perles, Moreno, Carvajal, \& Garcia-Viguera (2011) observed that green tea enriched with minimally-processed byproducts of broccoli had similar antioxidant capacity values as measured by the $\mathrm{DPPH}$ - assay to that of the control green tea. Interestingly, those beverages prepared with lower amounts of broccoli concentrate had significantly-higher antioxidant capacity than the control beverage. The authors reported that catechins were positively correlated with antioxidant capacity by $\mathrm{DPPH}$. for the different extracts. The observed results were attributed to synergistic and/or antagonistic effects by the type and ratio of bioactive compounds present in the different extracts under study (Dominguez-Perles, et al., 2011).

\subsection{Total Isothiocyanate Content (TICN)}

The total isothiocyanate contents of control and broccoli-enriched soups are displayed in Figure 1. A two-way ANOVA analysis of the TICN data revealed a significant interaction between sample and treatment (data not shown). Thus main effects for this 
data set were not further evaluated. It is clear though from the results presented in Figure 1 that broccoli-enriched soups resulted in a dramatic increase in the levels of total isothiocyanates compared to the control soups. Also, total isothiocyanate levels were significantly higher for all the broccoli floret-enriched soups $(0.21-0.29 \mu \mathrm{mol} / \mathrm{g}$ soup) compared to the stalk-enriched soups (0.09-0.11 $\mu \mathrm{mol} / \mathrm{g}$ soup).

These results are in agreement with the higher total glucosinolate content measured in broccoli floret compared to stalk tissue as previously described in this study (Table 1). No significant differences were found in the effect of microwave treatments (240 W, $400 \mathrm{~W}$ and $800 \mathrm{~W}$ ) in the case of control and stalk-enriched soups. However, in the case of broccoli floret-enriched soups, a significant difference was observed and soups prepared at 400 and $800 \mathrm{~W}$ had significantly higher total isothiocyanate content compared to $240 \mathrm{~W}$. At this level of energy input, it is possible that the differences observed may be due to different microwave treatments resulting in different temperature profiles, since higher temperature is achieved faster with increased power (watts) as previously shown by Verkerk \& Dekker (2004). Conversion of glucosinolates into isothiocyanates in broccoli freeze-dried powder has been previously report to be affected by temperature and maximum conversion was obtained at $45-50{ }^{\circ} \mathrm{C}$ (Alvarez-Jubete, Valverde, Smyth, \& Barry-Ryan, 2011). It is therefore possible that the temperature profile of those soups cooked at increased power may have been improved compared to lower power treatments in terms of isothiocyanate production.

Previously published studies have shown a large negative effect caused by microwave cooking on isothiocyanate production (Howard, et al., 1997; Jones, Faragher, \& Winkler, 2006; Jones, et al., 2010). However, much of the losses observed in isothiocyanate production in the above mentioned studies were attributed to leaching of glucosinolates into cooking water. In the present study, leaching of glucosinolates into cooking water does not represent a disadvantage with regards to isothiocyanate production since the cooking water remains an integral ingredient of the final product. The high levels of total isothiocyanates obtained in the present study also suggest that broccoli myrosinase remained active during the microwave treatments evaluated in this study. These results are in agreement with previously published data by Verkerk \& Dekker (2004) which show how myrosinase activity in microwaved Brassicas can 
be substantially maintained for selected energy inputs and power/time combinations. In particular, they showed how myrosinase activity was substantially retained in cabbage treated with energy inputs similar to the ones employed in this study were used while higher energy input treatments $(259.2 \mathrm{~kJ}, 4.8 \mathrm{~min}$ at $900 \mathrm{~W})$ resulted in a complete loss of hydrolytic activity.

\subsection{Sulforaphane}

The sulforaphane levels measured in the control, and broccoli-enriched soups (stalk and floret) are presented in Figure 1. The two-way analysis of variance of the sulforaphane data revealed no interaction between sample type and treatment. It also showed a non-significant effect for cooking treatment and a significant effect for sample type (Table 4). It can be observed from these results, that both enriched soups had dramatically higher levels of the bioactive sulforaphane compared to the control soups. The inclusion of broccoli floret and/or stalk freeze-dried powders in ready soup formulations can therefore result in a food product with high levels of health beneficial phytochemicals such as sulforaphane. Ready soups are an excellent food vehicle for these phytochemical-rich broccoli powders as the leaching of glucosinolates into the cooking water does not represent a loss of glucosinolates and therefore loss of sulforaphane production. Previous studies into the effect of microwave cooking (1100 W, 2-5 min) on sulforaphane production observed that leaching of glucosinolates into cooking water was one of the major factors leading to a dramatic reduction in sulforaphane production in microwave cooked broccoli (Jones, et al., 2010). The high levels of sulforaphane obtained in the present study for the broccoli-enriched soups (stalk and floret) indicate that the enzyme myrosinase responsible for the conversion of glucoraphanin into sulforaphane remains active during the microwave cooking treatment. Previously Verkerk \& Dekker (2004) had shown how myrosinase activity in microwaved Brassicas is greatly dependent not just on the energy input (power $\times$ time) but also on the temperature profiles associated with the different treatments. Verkerk \& Dekker (2004) showed that myrosinase activity in microwaved treated red cabbage was substantially maintained for energy inputs similar to the ones employed in the present study (circa $50 \mathrm{KJ}$ ). Also, in the present study the final temperature of the microwaved soup was $64 \pm 2{ }^{\circ} \mathrm{C}$ for any of the samples under study, therefore not reaching the temperature of $70{ }^{\circ} \mathrm{C}$ which had been previously reported to result in decreased formation of sulforaphane in broccoli 
florets (N. V. Matusheski, et al., 2004). It is interesting to note that sulforaphane production was lower in both broccoli floret and stalk freeze-dried powders hydrolysed at room temperature (3.42 and $1.13 \mu \mathrm{mol} / \mathrm{g}$ for floret and stalk powders respectively, add to materials and methods section) compared to sulforaphane production in broccoli-enriched soups. Since myrosinase co-factor ESP is more heat sensitive than myrosinase, it is possible that the rising temperature during the preparation of the soups may have inactivated myrosinase co-factor ESP to some degree while keeping myrosinase active (N. V. Matusheski, et al., 2004). Thus resulting in higher sulforaphane production in heat-treated samples (soups enriched with broccoli freeze-dried powders) compared to ambient temperature hydrolysed samples (freeze-dried powders). It is also interesting to note that the difference in sulforaphane production between freeze-dried powders hydrolysed at room temperature and freeze-dried powder in soup and hydrolysed at heated temperature was larger in the case of the broccoli floret compared to stalk. It is possible that the myrosinase system (e.g. myrosinase and ESP content and activity) may behave differently in floret and stalk. In addition, other factors related to physical and/or chemical aspects of the tissue such as tissue composition and structure may also affect glucosinolate conversion by affecting contact between substrate and enzyme.

Microwave cooking under the conditions evaluated in the present study therefore represents an adequate cooking method for broccoli-enriched ready soups to obtain a final product rich in sulforaphane. Also, the microwave treatments studied did not result in significant differences in the levels of sulforaphane production as can be observed in Figure 1. This observation also has practical implications from a consumer perspective as a range of microwave treatments (power level and cooking times) can therefore be employed to prepare a broccoli-enriched ready soup with high levels of sulforaphane.

Sulforaphane levels were significantly higher in broccoli floret-enriched soups compared to stalk-enriched soups. These results are in agreement with the levels of sulforaphane-precursor glucoraphanin detected in broccoli stalk and broccoli floret (Table 1). It is important to note that broccoli-stalk enriched soups still had significantly higher levels of sulforaphane compared to the control soups, therefore indicating that broccoli stalk represents an excellent source of glucosinolates and their 
hydrolysed products isothiocyanates. To date no study had previously evaluated sulforaphane production from broccoli stalk tissue. The results presented in this study suggest that broccoli stalk is an attractive alternative to broccoli floret as a source of health beneficial compounds since it is currently considered a byproduct of the broccoli crop.

\subsection{Sensory}

The acceptability scores of the soup samples as determined by the taste panelists are displayed in Table 5. The acceptability scores for colour were higher for the control soups, followed by stalk and floret-enriched soups, however, these differences were found to be non significant. With regards to aroma, acceptability scores were significantly higher for the control soups, with similar aroma scores for floret- and stalk-enriched soups. No significant differences were observed in consistency scores. Finally, overall acceptability scores were in the order control > stalk-enriched > floret-enriched. However it was interesting to find that the stalk-enriched soup was not significantly different from the control, nor was it significantly different from the floret-enriched soup. Floret-enriched soups did score significantly lower compared to control soup in overall acceptability. These results show that broccoli stalk powder may be introduced into a functional and convenient soups formulation to enhance the content of key bioactive compounds such as sulforaphane without adversely affecting the sensory properties of the food product. Another immediate advantage to the use of broccoli stalk may be that related to its price since it is currently considered a byproduct.

\section{Conclusions}

The results obtained in the present study indicate that in addition to broccoli floret, broccoli stalk represent an excellent source of glucosinolates and can be employed in the development of convenient functional foods rich in phytochemicals. The colour of the ready-soups was significantly affected with the addition of both broccoli floret and stalk powder and both $\mathrm{L}^{*}$ and $\mathrm{H}^{*}$ values were significantly higher for the broccoli floret enriched soups followed by stalk enriched and control soups. The inclusion of broccoli floret and broccoli stalk freeze-dried powders in ready-soup formulations resulted in food products rich in bioactive isothiocyanates, and in sulforaphane in particular. No significant differences in antioxidant capacity as measured by the 
ORAC assay were detected between broccoli-enriched (floret and stalk enriched) soups compared to the control soups. The different microwave treatments under study resulted in similar levels of bioactive compounds in the final soups thus suggesting that a range of microwave treatments can be employed in the preparation of these functional food products. Total isothiocyanate and sulforaphane levels were higher in broccoli floret enriched soups as compared to broccoli stalk enriched soups which is in agreement with the higher levels of total glucosinolates, and glucoraphanin levels respectively, measured in broccoli floret and stalk. Yet, broccoli stalk enriched soups had significantly higher sulforaphane and total isothiocyanate levels compared to control soups implying that broccoli stalk represents an attractive alternative to broccoli floret in the preparation of broccoli enriched functional soups, since broccoli stalk is currently considered a byproduct of the broccoli crop. Analysis of the results from the sensory panel revealed that stalk enriched soups showed that floret containing soups received significantly lower acceptability scores compared to the control soups. However, the overall acceptability of stalk-enriched soups was not significantly different to that of control soups.

\section{Acknowledgements}

This research was funded under the Irish National Development Plan under the Food Institutional Research Measure, administered by the Department of Agriculture, Fisheries and Food.

\section{References}

Alvarez-Jubete, L., Valverde, J., Smyth, T., \& Barry-Ryan, C. (2011). Optimization of Glucosinolate Bioconversion into Isothiocyanates Using Response Surface Methodology. Polish Journal of Food and Nutrition Science, 61(1S Special Issue), 71.

Bones, A. M., \& Rossiter, J. T. (2006). The enzymic and chemically induced decomposition of glucosinolates. Phytochemistry, 67(11), 1053-1067.

Brown, A. F., Yousef, G. G., Jeffrey, E. H., Klein, B. P., Wallig, M. A., Kushad, M. M., et al. (2002). Glucosinolate profiles in broccoli: Variation in levels and implications in breeding for cancer chemoprotection. Journal of the American Society for Horticultural Science, 127(5), 807-813.

Dominguez-Perles, R., Martinez-Ballesta, M. C., Carvajal, M., Garcia-Viguera, C., \& Moreno, D. A. (2010). Broccoli-Derived By-Products-A Promising Source of Bioactive Ingredients. Journal of Food Science, 75(4), C383-C392. doi: 10.1111/j.1750-3841.2010.01606.X 
Dominguez-Perles, R., Moreno, D. A., Carvajal, M., \& Garcia-Viguera, C. (2011). Composition and antioxidant capacity of a novel beverage produced with green tea and minimally-processed byproducts of broccoli. Innovative Food Science \&amp; Emerging Technologies, 12(3), 361-368. doi: 10.1016/j.ifset.2011.04.005

Fahey, J. W., Zalcmann, A. T., \& Talalay, P. (2001). The chemical diversity and distribution of glucosinolates and isothiocyanates among plants. Phytochemistry, 56(1), 5-51.

Faller, A. L. K., \& Fialho, E. (2009). The antioxidant capacity and polyphenol content of organic and conventional retail vegetables after domestic cooking. Food Research International, 42(1), 210-215. doi: 10.1016/j.foodres.2008.10.009

Galgano, F., Favati, F., Caruso, M., Pietrafesa, A., \& Natella, S. (2007). The influence of processing and preservation on the retention of health-promoting compounds in broccoli. Journal of Food Science, 72(2), S130-S135. doi: 10.1111/j.1750-3841.2006.00258.x

Holst, B., Fenwick, G. R., \& Benjamin, C. (2003). Glucosinolates Encyclopedia of Food Sciences and Nutrition (pp. 2922-2930). Oxford: Academic Press.

Holst, B., \& Williamson, G. (2004). A critical review of the bioavailability of glucosinolates and related compounds. Natural Product Reports, 21(3), 425447.

Howard, L. A., Jeffery, E. H., Wallig, M. A., \& Klein, B. P. (1997). Retention of phytochemicals in fresh and processed broccoli. Journal of Food Science, 62(6), 1098-+. doi: 10.1111/j.1365-2621.1997.tb12221.x

Huang, D., Ou, B., Hampsch-Woodill, M., Flanagan, J. A., \& Prior, R. L. (2002). High-Throughput Assay of Oxygen Radical Absorbance Capacity (ORAC) Using a Multichannel Liquid Handling System Coupled with a Microplate Fluorescence Reader in 96-Well Format. Journal of Agricultural and Food Chemistry, 50(16), 4437-4444. doi: 10.1021/jf0201529

Jeffery, E. H., \& Araya, M. (2009). Physiological effects of broccoli consumption. Phytochemistry Reviews, 8(1), 283-298. doi: 10.1007/s11101-008-9106-4

Jones, R. B., Faragher, J. D., \& Winkler, S. (2006). A review of the influence of postharvest treatments on quality and glucosinolate content in broccoli (Brassica oleracea var. italica) heads. Postharvest Biology and Technology, 41(1), 1-8. doi: 10.1016/j.postharvbio.2006.03.003

Jones, R. B., Frisina, C. L., Winkler, S., Imsic, M., \& Tomkins, R. B. (2010). Cooking method significantly effects glucosinolate content and sulforaphane production in broccoli florets. Food Chemistry, 123(2), 237-242. doi: 10.1016/j.foodchem.2010.04.016

Jung, S., Ghoul, M., \& de Lamballerie-Anton, M. (2003). Influence of high pressure on the color and microbial quality of beef meat. LWT - Food Science and Technology, 36(6), 625-631. doi: 10.1016/s0023-6438(03)00082-3

Kurilich, A. C., Jeffery, E. H., Juvik, J. A., Wallig, M. A., \& Klein, B. P. (2002). Antioxidant Capacity of Different Broccoli (Brassica oleracea) Genotypes Using the Oxygen Radical Absorbance Capacity (ORAC) Assay. Journal of Agricultural and Food Chemistry, 50(18), 5053-5057. doi: 10.1021/jf025535l

Kushad, M. M., Brown, A. F., Kurilich, A. C., Juvik, J. A., Klein, B. P., Wallig, M. A., et al. (1999). Variation of glucosinolates in vegetable crops of Brassica oleracea. Journal of Agricultural and Food Chemistry, 47(4), 1541-1548. doi: 10.1021/jf980985s 
Matusheski, N. V., \& Jeffery, E. H. (2001). Comparison of the bioactivity of two glucoraphanin hydrolysis products found in broccoli, sulforaphane and sulforaphane nitrile. J Agric Food Chem, 49(12), 5743 - 5749.

Matusheski, N. V., Juvik, J. A., \& Jeffery, E. H. (2004). Heating decreases epithiospecifier protein activity and increases sulforaphane formation in broccoli. Phytochemistry, 65(9), 1273-1281. doi: 10.1016/j.phytochem.2004.04.013

Matusheski, N. V., Swarup, R., Juvik, J. A., Mithen, R., Bennett, M., \& Jeffery, E. H. (2006). Epithiospecifier protein from broccoli (Brassica oleracea L. ssp italica) inhibits formation of the anticancer agent sulforaphane. Journal of Agricultural and Food Chemistry, 54(6), 2069-2076. doi: 10.1021/jf0525277

Matusheski, N. V., Wallig, M. A., Juvik, J. A., Klein, B. P., Kushad, M. M., \& Jeffery, E. H. (2001). Preparative HPLC Method for the Purification of Sulforaphane and Sulforaphane Nitrile from Brassica Oleracea. J. Agric. Food Chem., 49, 1867-1872.

McGuire, R. G. (1992). Reporting of Objective Color Measurements. HortScience, 27(12), 1254-1255.

Miglio, C., Chiavaro, E., Visconti, A., Fogliano, V., \& Pellegrini, N. (2008). Effects of different cooking methods on nutritional and physicochemical characteristics of selected vegetables. Journal of Agricultural and Food Chemistry, 56(1), 139-147. doi: 10.1021/jf072304b

Mohn, T., Cutting, B., Ernst, B., \& Hamburger, M. (2007). Extraction and analysis of intact glucosinolates - A validated pressurized liquid extraction/liquid chromatography-mass spectrometry protocol for Isatis tinctoria, and qualitative analysis of other cruciferous plants. Journal of Chromatography A, 1166(1-2), 142-151. doi: 10.1016/j.chroma.2007.08.028

Moreno, D. A., Carvajal, M., Lopez-Berenguer, C., \& Garcia-Viguera, C. (2006). Chemical and biological characterisation of nutraceutical compounds of broccoli. Journal of Pharmaceutical and Biomedical Analysis, 41(5), 15081522. doi: 10.1016/j.jpba.2006.04.003

Ou, B., Hampsch-Woodill, M., \& Prior, R. L. (2001). Development and Validation of an Improved Oxygen Radical Absorbance Capacity Assay Using Fluorescein as the Fluorescent Probe. Journal of Agricultural and Food Chemistry, 49(10), 4619-4626. doi: 10.1021/jf010586o

Rosa, E. A. S., \& Rodrigues, P. M. F. (1999). Towards a more sustainable agriculture system: The effect of glucosinolates on the control of soil-borne diseases. Journal of Horticultural Science \& Biotechnology, 74, 667-674.

Song, L., Morrison, J. J., Botting, N. P., \& Thornalley, P. J. (2005). Analysis of glucosinolates, isothiocyanates, and amine degradation products in vegetable extracts and blood plasma by LC-MS/MS. Analytical Biochemistry, 347(2), 234-243. doi: 10.1016/j.ab.2005.09.040

Vallejo, F., Tomas-Barberan, F. A., \& Garcia-Viguera, C. (2002). Glucosinolates and vitamin $\mathrm{C}$ content in edible parts of broccoli florets after domestic cooking. European Food Research and Technology, 215(4), 310-316. doi: 10.1007/s00217-002-0560-8

Verkerk, R., \& Dekker, M. (2004). Glucosinolates and myrosinase activity in red cabbage (Brassica oleracea L. var. Capitata f. rubra DC.) after various microwave treatments. Journal of Agricultural and Food Chemistry, 52(24), 7318-7323. doi: 10.1021/jf0493268 
Verkerk, R., Schreiner, M., Krumbein, A., Ciska, E., Holst, B., Rowland, I., et al. (2009). Glucosinolates in Brassica vegetables: The influence of the food supply chain on intake, bioavailability and human health. Molecular Nutrition \& Food Research, 53(S2), S219-S219. doi: 10.1002/mnfr.200800065

Wachtel-Galor, S., Wong, K. W., \& Benzie, I. F. F. (2008). The effect of cooking on Brassica vegetables. Food Chemistry, 110(3), 706-710. doi: 10.1016/j.foodchem.2008.02.056

Williams, D. J., Critchley, C., Pun, S., Chaliha, M., \& O'Hare, T. J. (2010). Key Role of Fe2+ in Epithiospecifier Protein Activity. Journal of Agricultural and Food Chemistry, 58(15), 8512-8521. doi: 10.1021/jf904532n

Zhang, D. L., \& Hamauzu, Y. (2004). Phenolics, ascorbic acid, carotenoids and antioxidant activity of broccoli and their changes during conventional and microwave cooking. Food Chemistry, 88(4), 503-509. doi: 10.1016/j.foodchem.2004.01.065

Zhang, Y., Cho, C.-G., Posner, G. H., \& Talalay, P. (1992). Spectroscopic quantitation of organic isothiocyanates by cyclocondensation with vicinal dithiols. Analytical Biochemistry, 205(1), 100-107. doi: 10.1016/00032697(92)90585-u

Zhang, Y., \& Tang, L. (2007). Discovery and development of sulforaphane as a cancer chemopreventive phytochemical. Acta Pharmacologica Sinica, 28(9), 1343-1354. doi: 10.1111/j.1745-7254.2007.00679.x

Zhang, Y., Wade, K. L., Prestera, T., \& Talalay, P. (1996). Quantitative Determination of Isothiocyanates, Dithiocarbamates, Carbon Disulfide, and Related Thiocarbonyl Compounds by Cyclocondensation with 1,2Benzenedithiol. Analytical Biochemistry, 239(2), 160-167. doi: 10.1006/abio.1996.0311

Zhang, Y. S., Cho, C. G., Posner, G. H., \& Talalay, P. (1992). SPECTROSCOPIC QUANTITATION OF ORGANIC ISOTHIOCYANATES BY CYCLOCONDENSATION WITH VICINAL DITHIOLS. Analytical Biochemistry, 205(1), 100-107. 
1 Table 1. Glucosinolate composition ( $\mu \mathrm{mol} / \mathrm{g} \mathrm{DW}$ ) of broccoli floret and by-products (Parthenon cultivar)

\begin{tabular}{ccccccc}
\hline & & & & & & $\begin{array}{c}\text { Relative } \\
\text { abundance }\end{array}$ \\
& Glucoraphanin $^{\mathrm{a}}$ & Glucobrassicin $^{\mathrm{b}}$ & 4-Methoxyglucobrassicin $^{\mathrm{c}}$ & Neoglucobrassicin $^{\mathrm{d}}$ & $\begin{array}{c}\text { Total } \\
\text { glucosinolates }\end{array}$ & $\begin{array}{c}\text { glucoraphanin } \\
(\%)\end{array}$ \\
\hline Floret & $4.92 \pm 0.55$ & $4.52 \pm 0.24$ & $0.37 \pm 0.00$ & $1.16 \pm 0.07$ & 10.97 & 44.85 \\
Stalk & $3.00 \pm 0.06$ & $0.55 \pm 0.09$ & $0.14 \pm 0.01$ & $0.24 \pm 0.03$ & 3.93 & 76.34 \\
Leaves & $1.26 \pm 0.09$ & $1.72 \pm 0.29$ & $0.08 \pm 0.02$ & $0.21 \pm 0.05$ & 3.27 & 38.53 \\
\hline
\end{tabular}

2 4-Methylsulfinylbutyl-glucosinolate

3 b3-Indolylmethyl-glucosinolate

4 c4-Methoxy-3-indolylmethyl-glucosinolate

$5{ }^{\mathrm{d}} \mathrm{N}$-Methoxy-3-indolylmethyl-glucosinolate

6 Values are means $(n=3) \pm S D$ 
Table 2. Instrumental colour analysis of control, broccoli floret- and stalk-enriched soups

\begin{tabular}{|c|c|c|c|c|c|c|c|c|c|}
\hline & \multicolumn{3}{|c|}{ Control } & \multicolumn{3}{|c|}{ Floret } & \multicolumn{3}{|c|}{ Stalk } \\
\hline & $240 \mathrm{~W}$ & $400 \mathrm{~W}$ & $800 \mathrm{~W}$ & $240 \mathrm{~W}$ & $400 \mathrm{~W}$ & $800 \mathrm{~W}$ & $240 \mathrm{~W}$ & $400 \mathrm{~W}$ & $800 \mathrm{~W}$ \\
\hline $\mathrm{L}^{*}$ & $79.09^{a} \pm 0.08$ & $79.05^{\mathrm{a}} \pm 0.15$ & $79.08^{\mathrm{a}} \pm 0.09$ & $58.62^{d} \pm 0.37$ & $59.18^{\mathrm{cd}} \pm 0.04$ & $59.8^{c} \pm 0.15$ & $69.07^{\mathrm{b}} \pm 0.42$ & $68.76^{\mathrm{b}} \pm 0.18$ & $69.17^{\mathrm{b}} \pm 0.76$ \\
\hline$a^{*}$ & $-1.39^{\mathrm{a}} \pm 0.02$ & $-1.41^{\mathrm{a}} \pm 0.02$ & $-1.44^{\mathrm{a}} \pm 0.06$ & $-7.48^{\mathrm{C}} \pm 0.15$ & $-7.54^{\mathrm{C}} \pm 0.11$ & $-7.55^{\mathrm{c}} \pm 0.06$ & $-4.42^{\mathrm{b}} \pm 0.28$ & $-4.45^{\mathrm{b}} \pm 0.26$ & $-4.34^{\mathrm{b}} \pm 0.14$ \\
\hline$b^{*}$ & $14.54^{\mathrm{c}} \pm 0.20$ & $14.54^{\mathrm{c}} \pm 0.19$ & $14.45^{\mathrm{c}} \pm 0.16$ & $23.89^{\mathrm{a}} \pm 0.17$ & $23.84^{\mathrm{a}} \pm 0.17$ & $23.70^{\mathrm{a}} \pm 0.23$ & $22.31^{\mathrm{b}} \pm 0.28$ & $22.41^{\mathrm{b}} \pm 0.24$ & $22.18^{\mathrm{b}} \pm 0.40$ \\
\hline $\mathrm{H}^{*}$ & $95.47^{\mathrm{c}} \pm 0.13$ & $95.54^{\mathrm{c}} \pm 0.06$ & $95.71^{\mathrm{c}} \pm 0.20$ & $107.38^{\mathrm{a}} \pm 0.20$ & $107.55^{\mathrm{a}} \pm 0.12$ & $107.68^{\mathrm{a}} \pm 0.02$ & $100.95^{b} \pm 0.37$ & $101.23^{\mathrm{b}} \pm 0.60$ & $101.06^{\mathrm{b}} \pm 0.17$ \\
\hline $\mathrm{C}^{*}$ & $14.61^{\mathrm{c}} \pm 0.20$ & $14.61^{\mathrm{c}} \pm 0.19$ & $14.52^{c} \pm 0.16$ & $25.03^{\mathrm{a}} \pm 0.21$ & $25.00^{\mathrm{a}} \pm 0.19$ & $24.88^{\mathrm{a}} \pm 0.23$ & $22.73^{\mathrm{b}} \pm 0.31$ & $22.85^{\mathrm{b}} \pm 0.26$ & $22.60^{\mathrm{b}} \pm 0.41$ \\
\hline$\Delta \mathrm{E}$ & - & - & - & $23.31^{\mathrm{a}} \pm 0.43$ & $22.77^{\mathrm{a}} \pm 0.06$ & $22.24^{\mathrm{a}} \pm 0.23$ & $14.88^{\mathrm{b}} \pm 0.58$ & $15.16^{\mathrm{b}} \pm 0.36$ & $14.77^{\mathrm{b}} \pm 0.81$ \\
\hline
\end{tabular}

Values are means $(\mathrm{n}=3) \pm \mathrm{SD}$. Means with different lower-case letters are statistically different at $\mathrm{P}<0.05$. 
Table 3. Antioxidant capacity as measured by ORAC assay of control, broccoli floret- and stalk-enriched soups

ORAC $^{1)}$ Control Floret Stalk

$240 \mathrm{~W} \quad 3.63^{\mathrm{abc}} \pm 0.36 \quad 4.00^{\mathrm{ab}} \pm 0.16 \quad 2.87^{\mathrm{cd}} \pm 0.04$

$400 \mathrm{~W} \quad 3.41^{\text {abcd }} \pm 0.31 \quad 4.17^{\mathrm{a}} \pm 0.25 \quad 2.49^{\mathrm{d}} \pm 0.12$

$800 \mathrm{~W} \quad 3.67^{\mathrm{abc}} \pm 0.42 \quad 3.67^{\mathrm{abc}} \pm 0.39 \quad 3.05^{\mathrm{bcd}} \pm 0.14$

Values are means $(\mathrm{n}=3) \pm$ SD. Means with different lower-case letters are statistically different at $\mathrm{P}<0.05$

${ }^{1)}$ Expressed as $\mu \mathrm{mol}$ Trolox Equivalent/g soup 
Figure 1. Total isothiocyanate content and sulforaphane levels in control, broccoli floret- and stalk-enriched soups.

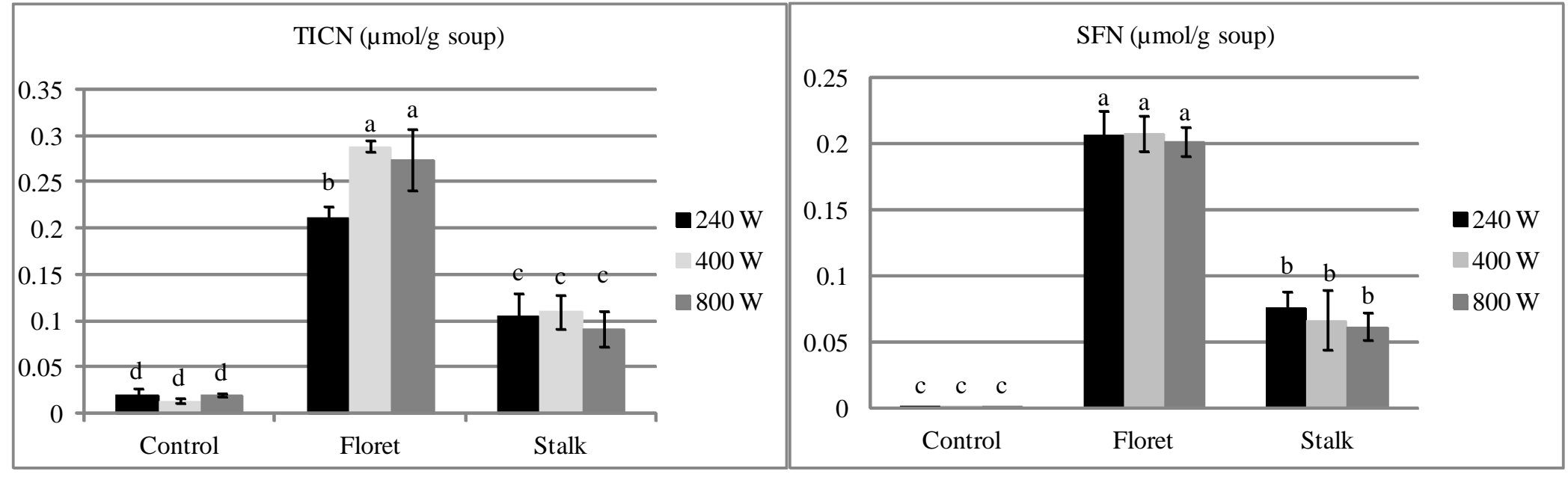

Values are means $(\mathrm{n}=3) \pm \mathrm{SD}$. Means with different lower-case letters are statistically different at $\mathrm{P}<0.05$ 
Figure 2. Chromatogram with MRM transitions for sulforaphane in broccoli stalk-enriched soups 260112022

MRM of 4 Channels ES+
0.56
$178.01>114.031$ (sulphoraphane)

100

$178.01>114.031$ (sulphoraphant

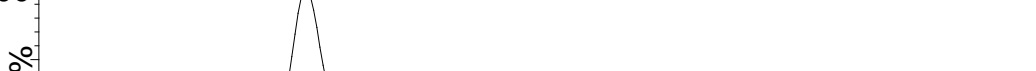

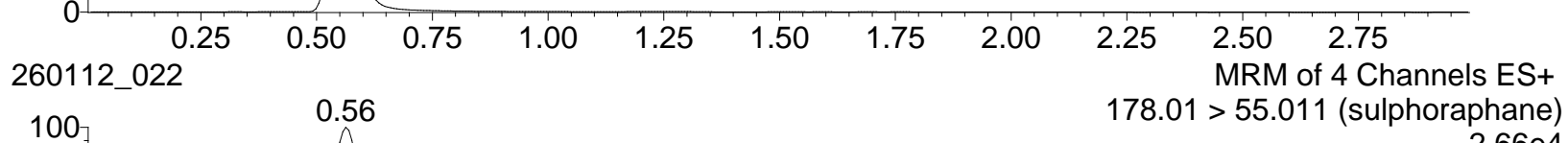

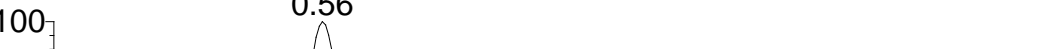

0.25

$1.00 \quad 1.25 \quad 1.50$

1.75

$2.50 \quad 2.75$ 
Table 4. Effect of sample type on colour, ORAC and sulforaphane values

\begin{tabular}{lccccc} 
& Control & Floret & Stalk & SE $^{1)}$ & $\mathrm{P}^{2)}$ \\
\hline $\mathrm{a}^{*}$ & $-1.42^{\mathrm{a}}$ & $-7.52^{\mathrm{c}}$ & $-4.41^{\mathrm{b}}$ & 0.07 & $<0.000$ \\
$\mathrm{~b}^{*}$ & $14.52^{\mathrm{c}}$ & $23.81^{\mathrm{a}}$ & $22.30^{\mathrm{b}}$ & 0.11 & $<0.000$ \\
$\mathrm{H}^{*}$ & $95.57^{\mathrm{c}}$ & $107.54^{\mathrm{a}}$ & $101.08^{\mathrm{b}}$ & 0.12 & $<0.000$ \\
$\mathrm{C}^{*}$ & $14.58^{\mathrm{c}}$ & $24.98^{\mathrm{a}}$ & $22.73^{\mathrm{b}}$ & 0.11 & $<0.000$ \\
$\Delta \mathrm{E}$ & - & 22.78 & 14.93 & 0.11 & $<0.000$ \\
ORAC $^{3)}$ & $3.57^{\mathrm{b}}$ & $3.95^{\mathrm{a}}$ & $2.80^{\mathrm{c}}$ & 0.13 & $<0.05$ \\
SFN $^{4)}$ & $0.00^{\mathrm{c}}$ & $0.20^{\mathrm{a}}$ & $0.07^{\mathrm{b}}$ & 0.01 & $<0.000$ \\
\hline
\end{tabular}

Values are means of 9 replicates. Means with different lower-case letters are statistically different.

${ }^{1)}$ Standard error

${ }^{2)}$ Significance

${ }^{3)}$ Expressed as $\mu \mathrm{mol}$ Trolox Equivalent/g soup

${ }^{4)}$ Expressed as $\mu \mathrm{mol}$ Sulforaphane Equivalent/g soup 
Table 5. Sensory acceptability of the control, broccoli floret- and stalk-enriched soups

\begin{tabular}{lccccc}
\hline \multicolumn{1}{c}{ Acceptability } & Control & Floret & Stalk & $\mathrm{P}$ & $\mathrm{SE}$ \\
\hline Colour & $3.6^{\mathrm{a}} \pm 0.9$ & $2.9^{\mathrm{a}} \pm 1.4$ & $3.2^{\mathrm{a}} \pm 1.2$ & $>0.05$ & 0.37 \\
Aroma & $4.0^{\mathrm{a}} \pm 0.9$ & $2.3^{\mathrm{b}} \pm 1.0$ & $2.5^{\mathrm{b}} \pm 0.8$ & $<0.0005$ & 0.30 \\
Consistency & $2.9^{\mathrm{a}} \pm 1.1$ & $2.9^{\mathrm{a}} \pm 1.2$ & $3.1^{\mathrm{a}} \pm 0.8$ & $>0.05$ & 0.33 \\
Overall acceptability & $3.4^{\mathrm{a}} \pm 1.0$ & $2.6^{\mathrm{b}} \pm 1.1$ & $3.0^{\mathrm{ab}} \pm 0.9$ & $<0.05$ & 0.33 \\
\hline
\end{tabular}

